\title{
New directions in self-regulation: the role of metamotivational beliefs
}

Article

Accepted Version

Scholer, A. A., Miele, D. B., Murayama, K. and Fujita, K. (2018) New directions in self-regulation: the role of metamotivational beliefs. Current Directions in Psychological Science, 27 (6). pp. 437-442. ISSN 0963-7214 doi: https://doi.org/10.1177/0963721418790549 Available at https://centaur.reading.ac.uk/77658/

It is advisable to refer to the publisher's version if you intend to cite from the work. See Guidance on citing.

To link to this article DOI: http://dx.doi.org/10.1177/0963721418790549

Publisher: Sage

All outputs in CentAUR are protected by Intellectual Property Rights law, including copyright law. Copyright and IPR is retained by the creators or other copyright holders. Terms and conditions for use of this material are defined in the End User Agreement.

\section{www.reading.ac.uk/centaur}

\section{CentAUR}

Central Archive at the University of Reading 
Reading's research outputs online 
Word Count: 2498

New Directions in Self-Regulation: The Role of Metamotivational Beliefs

\author{
Abigail A. Scholer \\ University of Waterloo \\ David B. Miele \\ Boston College \\ Kou Murayama \\ University of Reading \\ Kentaro Fujita \\ The Ohio State University
}




\begin{abstract}
Research on self-regulation has primarily focused on how people exert control over their thoughts, emotions, and behavior. Less attention has been paid to the ways in which people manage their motivational states in the service of achieving valued goals. In the present paper, we explore an emerging line of research that focuses on people's beliefs about their own motivation (i.e., their metamotivational knowledge), as well as the influence of these beliefs on their selection of regulatory strategies. In particular, we review evidence showing that people are often quite sensitive to the fact that distinct motivational states (e.g., eagerness vs. vigilance) are adaptive for different kinds of tasks. We also discuss how other metamotivational beliefs are inaccurate on average (e.g., beliefs about how rewards affect intrinsic motivation). Finally, we consider the implications of metamotivation research for the field of self-regulation and discuss future directions.
\end{abstract}

Keywords: motivation, self-regulation, self-control, regulatory focus, metacognition, intrinsic motivation 
New Directions in Self-Regulation: The Role of Metamotivational Beliefs These days, it is common to hear people_researchers, the media, perhaps one's reflection in the mirror-bemoan how poorly individuals fare in challenging self-regulation situations. Furthermore, there is much evidence suggesting that failing to regulate goals effectively leads to significant negative consequences at both an individual and societal level. Self-regulation failures prevent people from achieving a variety of important life goals (e.g., physical, social, and financial well-being) and play a role in many of the leading causes of death in North America (Mokdad, Marks, Stroup, \& Gerberding, 2004). Yet researchers have also learned a lot about how people — quite frequently — get it right. In particular, they have focused on how people effectively manage their goals by regulating their thoughts (Flavell, 1979), emotions (Tamir, 2016), and behaviors (Carver \& Scheier, 1998). However, until recently, there has been relatively little research focusing on whether or how people attempt to regulate their own motivations. In part, this may stem from a sense that motivation itself is an elusive target, that it is not possible to direct what one wants. In contrast, we propose that people may indeed be able to regulate what they want and that the study of such motivation regulation is an essential aspect of understanding human triumphs and foibles.

Specifically, we argue that a more complete understanding of when — and why — people succeed or fail at self-regulation involves the study of metamotivation, a developing frontier of motivation science research (Ayduk \& Kross, 2010; Kim, Brady, \& Wolters, 2018; D. MacGregor, 1960; K. E. MacGregor, Carnevale, Dusthimer, \& Fujita, 2017; Miele \& Scholer, 2016, 2018; Mischel \& Mischel, 1983; Murayama, 2014; Murayama, Kitagami, Tanaka, \& Raw, 2016; Nguyen, Carnevale, Scholer, Miele, \& Fujita, 2018; Scholer \& Miele, 2016; Thoman, Sansone, \& Geerling, 2017; Wolters, 2003). Integrating insights from work in cognitive, 
developmental, educational, and social psychology, we conceptualize metamotivation as the processes by which individuals monitor and control their motivational states in order to achieve their goals (Miele \& Scholer, 2018; Scholer \& Miele, 2016). The "motivation" element of metamotivation reflects the key idea that motivation is the target of regulation. The means by which people regulate their motivation may be cognitive or behavioral; importantly, however, the targets of this regulation are the quantity (i.e., more or less) and quality (i.e., type) of their motivation.

We propose that the efficacy of these metamotivational processes - and the success of goal pursuit more generally_depends in part on what people know and believe about the nature of motivation (i.e., their metamotivational knowledge and beliefs). Emerging research suggests that there is important variability in the accuracy of these beliefs. On the one hand, people often utilize appropriate strategies to increase desired motivations (e.g., adopting a big-picture motivational focus when anticipating self-control conflicts) and are quite sensitive to the fact that qualitatively distinct motivational states may lead to optimal performance on different kinds of tasks (e.g., that eagerness versus vigilance motivation promotes performance when brainstorming). On the other hand, people seem to hold inaccurate illusions about other aspects of motivation regulation (e.g., not recognizing the situations in which extrinsic rewards tend to undermine intrinsic motivation).

\section{When people regulate motivation, what are they regulating?}

Regulating motivational quantity typically involves knowing what types of strategies can increase motivation (e.g., Schwinger \& Otterpohl, 2017), whereas regulating motivational quality requires that people also understand that motivation not only differs in level, but also in type. Indeed, several prominent theories of motivation and cognition (e.g., self-determination 
theory; regulatory focus theory; construal level theory) distinguish between qualitatively different motivational states (e.g., intrinsic versus extrinsic motivation; eager versus vigilant motivation; high-level versus low-level construal) that can be increased or decreased via distinct strategies and have differential consequences for goal pursuit and performance.

Although certain motivational states (e.g., eager approach motivation) are frequently heralded as generally beneficial, motivational states typically involve context-specific trade-offs (e.g., Sansone, 2009; Scholer \& Higgins, 2012; Scholer et al., 2014). In other words, motivational states are not universally effective; rather, the effectiveness of a motivational state often depends on the particular demands of a situation (see also Bonanno \& Burton, 2013). For example, whereas eager motivational states (enthusiastically seeking opportunities for gain) tend to enhance performance in situations requiring divergent thinking (e.g., a creative brainstorming task), vigilant motivational states (carefully protecting against potential losses) are more likely to enhance performance in situations characterized by convergent thinking (e.g., logic problems; Beuk \& Basadur, 2016; Semin, Higgins, de Montes, Estourget, \& Valencia, 2005).

The existence of motivational trade-offs such as these has two important implications for metamotivation. First, it suggests that the effective regulation of motivation involves knowledge of how different motivational states positively or negatively affect the performance of specific tasks in particular contexts (task knowledge). Further, identifying the optimal motivational state for a given context is not enough; people must be able to draw on their understanding of what it is like to experience this state (self knowledge) in order determine whether they are currently experiencing it; and, if not, they must find ways to induce the state in themselves (strategy knowledge; Miele \& Scholer, 2018; Wolters, 2003; see also Flavell, 1979; Pintrich, 2002). Second, it suggests that the effective regulation of motivation in the long-term involves 
significant flexibility — putting this knowledge of upsides and downsides into action so that one's motivational state optimally fits with the motivational affordances of different situations one encounters. In other words, a central metamotivational challenge is recognizing that the type and amount of motivation that best promotes goal outcomes in the present context may differ from the motivational state that was best suited for the previous context (Miele \& Scholer, 2018).

Some aspects of one's metamotivational knowledge may be tacit or implicit (e.g., Reber, 1989; Wagner \& Sternberg, 1985). In such cases, metamotivational knowledge can be assessed by presenting participants with scenarios describing different motivational challenges and asking them to indicate which types of responses feel right or would lead to optimal performance (K. E. MacGregor et al., 2017; Nguyen et al., 2018; Scholer \& Miele, 2016). Participants with accurate knowledge tend to endorse the most appropriate response when presented with different scenarios, even if they are not aware that they possess this knowledge or cannot articulate it spontaneously.

\section{Metamotivational Beliefs: When People Get it Right versus Wrong}

Across several distinct lines of research, evidence is emerging that people have both accurate and inaccurate beliefs about how to regulate their motivation. On the one hand, people are often remarkably sensitive to the qualitatively different motivational demands of different tasks. On the other hand, individuals also hold some inaccurate beliefs about how certain motivational states operate and how to best manage them. Examining these beliefs opens up new possibilities for intervening to improve self-regulation, a point we return to in the final section.

Accurate Beliefs about Task-Motivation Fit. A significant body of work provides evidence that being in the right type of motivational state for the situation at hand leads to increased engagement and performance (e.g., Higgins, 2000; Motyka et al., 2014). While in 
earlier work individuals were generally considered to be passive players in this process, the metamotivational approach highlights individuals as active agents that assess the motivational demands of the task at hand and regulate their motivational orientations in order to best negotiate these demands and maximize performance (Scholer \& Miele, 2016). This research suggests that in many ways, people are quite sensitive to how qualitatively different motivational states fit different situations and tasks. For instance, participants in a series of studies by Scholer and Miele (2016) recognized that inducing vigilant motivational states (e.g., by recalling times they avoided getting into trouble or adopting an incentive structure that made losses salient) would lead them to perform better on tasks that required convergent (rather than divergent) processing (e.g., proofreading), whereas inducing eager motivational states (e.g., by recalling times they made progress towards life success or adopting an incentive structure that made gains salient) would lead them to perform better on tasks that required divergent processing (e.g., brainstorming).

Related programs of research provide further illustrations of how individuals are sensitive to other aspects of task-motivation fit. For example, individuals hold accurate metamotivational knowledge about the qualitative aspects of motivation that facilitate success in self-control conflicts - conflicts between relatively immediate, local concerns versus distant, global goals (Fujita, 2011). Research on construal level theory has revealed that individuals are more likely to successfully resolve these kinds of conflicts when engaged in high-level relative to low levelconstrual (i.e., when tuned to the abstract and essential rather than concrete idiosyncratic features of events; Fujita, Trope, Liberman, \& Levin-Sagi, 2006). Overall, people do indeed correctly recognize that high-level versus low-level construal promote self-control (Fujita, Scholer, Miele, \& Nguyen, 2018; K. E. MacGregor et al., 2017; Nguyen et al., 2018). For instance, participants 
indicate that tactics known to induce high-level vs. low-level construal (e.g., using abstract versus concrete language, focusing on "why" versus "how," or generating categories versus exemplars) will enhance self-control. Importantly, individuals who have more accurate metamotivational knowledge about the role of construal in self-control evidence better outcomes for valued goals (e.g., reduced body mass index and higher grades; K.E. MacGregor et al.). This provides evidence that accurate metamotivational knowledge can lead to more effective selfregulation.

Individuals also appear to have some metamotivational sensitivity about situations in which intrinsic versus extrinsic motivation may be particularly beneficial for performance. Although intrinsic motivation can increase engagement and help to buffer individuals against setbacks (Burton, Lydon, D’Alessandro, \& Koestner, 2006), it does not always predict high performance (Burton et al., 2006; Sansone, Smith, Thoman, \& MacNamara, 2012). Intrinsic motivation may have few, if any, downsides when there is no time pressure or rigid performance appraisal criteria. However, under conditions in which enhancing interest is at odds with performance appraisal criteria, individuals who focus only on intrinsic motivation may not perform as well (Sansone, 2009; Sansone et al., 2012). Edwards, Scholer, and Miele (2018) observed that individuals appear to recognize some of these dynamics - correctly identifying situations in which intrinsic versus extrinsic motivation would be most beneficial for performance, and identifying the types of strategies that could be used to increase intrinsic versus extrinsic motivation, respectively.

Inaccurate Metamotivational Beliefs. While the research reviewed above suggests that individuals can be quite sensitive to the trade-offs of qualitatively distinct motivational states, emerging research reveals that people also hold some inaccurate beliefs about motivation 
(Murayama et al., 2016; Murayama, Kuratomi, Johnsen, Kitagami, \& Hatano, 2018; Scholer \& Miele, 2016; Woolley \& Fishbach, 2015). For instance, individuals appear to be overly pessimistic about their ability to sustain intrinsic motivation in the absence of extrinsic incentives (Murayama et al., 2018). Further, individuals fail to recognize that intrinsic motivation can actually be undermined by extrinsic incentives (Murayama et al., 2016) and fail to appreciate the value of intrinsic incentives when anticipating future tasks (Woolley \& Fishbach, 2015). They also fail to appreciate the benefits of setting self-concordant (i.e., autonomous) goals to satisfy their needs (Werner \& Milyavskaya, in press). In addition, even when people are sensitive to task-motivation fit, they still strongly endorse the general utility of eager motivational states across most situations (at least in North America; Scholer \& Miele, 2016). These kinds of beliefs may lead people to select and execute metamotivational control strategies that are ineffective or even counterproductive.

\section{Contributions to Existing Literature and Future Directions}

A primary contribution of the metamotivational approach is that it highlights how effective self-regulation involves not only the regulation of emotion, cognition, and behavior, but also motivation. Emerging research reveals that in attempting to regulate their motivations people hold both accurate and inaccurate beliefs. Investigating this metamotivational knowledge has significant implications for understanding how to help individuals be more successful in the pursuit of their goals.

A second key advancement of the metamotivational approach is highlighting the role of knowledge as a source of self-regulation success versus failure. In contrast to research on selfregulation that focuses on individual differences in capacity, the metamotivational approach focuses on understanding what people know about motivation as a pre-condition of effective 
regulation. Incorrect beliefs about how rewards work or about what type of motivation fits a given situation not only increase the likelihood of self-regulation failure, but may also predict resistance to certain types of interventions. Key questions to explore in future research are how individuals develop metamotivational knowledge, how metamotivational knowledge in one domain (e.g., beliefs about eager motivation) relates to metamotivational knowledge in another (e.g., beliefs about intrinsic motivation), and how metamotivational knowledge relates to various socially-valued outcomes, such as physical health, academic achievement, and job performance.

A third implication of the metamotivational approach is that it allows fine-grained predictions about the specific tasks on which a particular individual is likely to succeed or fail, rather than classifying individuals as generally good or bad at self-regulation more generally. For instance, some individuals may have accurate knowledge about how to most effectively utilize and sustain eager motivation. However, these same individuals may struggle to identify situations that would be better met with vigilance motivation or know what kinds of strategies could be used to increase vigilance. Thus, the overall success and well-being of these individuals may be largely dependent on the types of situations they encounter. In a world of eager tasks, they may soar; however, change the situations that these individuals encounter and suddenly their outcomes may look quite different. Thus, by taking context-specific beliefs as a starting point, researchers may be able to develop interventions that more carefully target the particular vulnerabilities individuals face.

A related contribution of the metamotivational approach is the prominence it gives to the role of flexibility in self-regulatory success. As the prior example suggests, and as others have argued with respect to emotion regulation strategies (Bonanno \& Burton, 2013), no motivational state or strategy is universally effective. Even if an individual possesses accurate knowledge 
about a broad range of contexts, a key challenge in self-regulation is being able to flexibly implement this knowledge in real time. Moving forward, it will be important to identify what factors enable individuals to inhibit their motivational approach from a prior task in order to induce motivational states that are more appropriate for the current task. Perhaps some individuals (e.g., those higher in executive functioning) will be better able than others at deploying their motivational knowledge. It is also possible that some situations facilitate translation of knowledge more than others.

In conclusion, although prior work in motivation science has done much to identify different types of motivational states and to document the antecedents and consequences of these states, less is known about people's understanding of motivation and their strategic attempts to harness the optimal motivational state for a given situation. This is a critical question; what people know about motivation may determine how effectively they are able to manage it. Recent research in metamotivation highlight the importance of exploring the role of motivation regulation in understanding both when and why goal pursuit goes well and goes awry. 


\section{References}

Ayduk, Ö., \& Kross, E. (2010). From a distance: Implications of spontaneous self-distancing for adaptive self-reflection. Journal of Personality and Social Psychology, 98(5), 809-829.

Beuk, F., \& Basadur, T. (2016). Regulatory focus, task engagement and divergent thinking. Creativity and Innovation Management, 25(2), 199-210.

Bonanno, G. A., \& Burton, C. L. (2013). Regulatory flexibility: An individual differences perspective on coping and emotion regulation. Perspectives on Psychological Science, $8(6), 591-612$.

Burton, K. D., Lydon, J. E., D’Alessandro, D. U., \& Koestner, R. (2006). The differential effects of intrinsic and identified motivation on well-being and performance: Prospective, experimental, and implicit approaches to self-determination theory. Journal of Personality and Social Psychology, 91(4), 750-762.

Carver, C. S., \& Scheier, M. F. (1998). On the self-regulation of behavior. New York: Cambridge University Press. R

Edwards, J., Scholer, A. A., \& Miele, D. B. (2018). Metamotivation about intrinsic-extrinsic trade-offs. Manuscript in Preparation.

Flavell, J. H. (1979). Metacognition and cognitive monitoring: A new area of cognitivedevelopmental inquiry. American Psychologist, 34(10), 906-911.

Fujita, K. (2011). On conceptualizing self-control as more than the effortful inhibition of impulses. Personality and Social Psychology Review, 15(4), 352-366.

Fujita, K., Scholer, A. A., Miele, D. B., \& Nguyen, T. (2018). On metamotivation: Consumers' knowledge of the role of construal level in self-regulation. Under Review. 
Fujita, K., Trope, Y., Liberman, N., \& Levin-Sagi, M. (2006). Construal levels and self-control. Journal of Personality and Social Psychology, 90(3), 351-367.

Higgins, E. T. (2000). Making a good decision: Value from fit. American Psychologist, 55(11), $1217-1230$.

Kim, Y., Brady, A. C., \& Wolters, C. A. (2018). Development and validation of the brief regulation of motivation scale. Learning and Individual Differences.

MacGregor, D. (1960). The human side of enterprise. New York.

MacGregor, K. E., Carnevale, J. J., Dusthimer, N. E., \& Fujita, K. (2017). Knowledge of the self-control benefits of high-level versus low-level construal. Journal of Personality and Social Psychology, 112(4), 607-620.

Miele, D. B., \& Scholer, A. A. (2016). Self-regulation of motivation. In K. R. Wentzel \& D. B. Miele (Eds.), Handbook of Motivation at School (pp. 363-384). New York, NY: Taylor \& Francis.

Miele, D. B., \& Scholer, A. A. (2018). The role of metamotivational monitoring in motivation regulation. Educational Psychologist, 53(1), 1-21.

Mischel, H. N., \& Mischel, W. (1983). The development of children's knowledge of self-control strategies. Child Development, 54(3), 603-619.

Mokdad, A. H., Marks, J. S., Stroup, D. F., \& Gerberding, J. L. (2004). Actual causes of death in the United States, 2000. JAMA: The Journal of the American Medical Association, 291(10), 1238-1245.

Motyka, S., Grewal, D., Puccinelli, N. M., Roggeveen, A. L., Avnet, T., Daryanto, A., ... Wetzels, M. (2014). Regulatory fit: A meta-analytic synthesis. Journal of Consumer Psychology, 24(3), 394-410. 
Murayama, K. (2014). Knowing your motivation: Metamotivation. Annual Review of Japanese Child Psychology (Special Issue on Motivation and Psychology), 112-116.

Murayama, K., Kitagami, S., Tanaka, A., \& Raw, J. A. L. (2016). People's naivete about how extrinsic rewards influence intrinsic motivation. Motivation Science, 2, 138-142.

Murayama, K., Kuratomi, K., Johnsen, L., Kitagami, S., \& Hatano, A. (2018). People underestimate our capability to motivate ourselves without extrinsic incentives. Under Review.

Nguyen, T., Carnevale, J. J., Scholer, A. A., Miele, D. B., \& Fujita, K. (2018). Metamotivational understanding of the role of high-level and low-level construal in self-control and behavioral execution. Manuscript in preparation.

Pintrich, P. R. (2002). Future challenges and directions for theory and research on personal epistemology. In B. K. Hofer \& P. R. Pintrich (Eds.), Personal epistemology: The psychology of beliefs about knowledge and knowing (pp. 389-414). Mahwah, NJ: Lawrence Erlbaum Associates Publishers.

Reber, A. S. (1989). Implicit learning and tacit knowledge. Journal of Experimental Psychology: General, 118(3), 219-235.

Sansone, C. (2009). What's interest got to do with it?: Potential trade-offs in the self-regulation of motivation. In J. P. Forgas, R. F. Baumeister, \& D. M. Tice (Eds.), Psychology of selfregulation: Cognitive, affective, and motivational processes (pp. 35-51). New York, NY,: Psychology Press.

Sansone, C., Smith, J. L., Thoman, D. B., \& MacNamara, A. (2012). Regulating interest when learning online: Potential motivation and performance trade-offs. The Internet and Higher Education, 15(3), 141-149. 
Scholer, A. A., \& Higgins, E. T. (2012). Too much of a good thing? Trade-offs in promotion and prevention focus. In R. M. Ryan (Ed.), The Oxford handbook of human motivation (pp. 65-84). New York, NY: Oxford University Press.

Scholer, A. A., \& Miele, D. B. (2016). The role of metamotivation in creating task-motivation fit. Motivation Science, 2(3), 171-197.

Scholer, A. A., Ozaki, Y., \& Higgins, E. T. (2014). Inflating and deflating the self: Sustaining motivational concerns through self-evaluation. Journal of Experimental Social Psychology, 51, 60-73.

Schwinger, M., \& Otterpohl, N. (2017). Which one works best? Considering the relative importance of motivational regulation strategies. Learning and Individual Differences, $53,122-132$.

Semin, G. R., Higgins, E. T., de Montes, L. G., Estourget, Y., \& Valencia, J. F. (2005). Linguistic signatures of regulatory focus: How abstraction fits promotion more than prevention. Journal of Personality and Social Psychology, 89(1), 36-45.

Tamir, M. (2016). Why do people regulate their emotions? A taxonomy of motives in emotion regulation. Personality and Social Psychology Review, 20(3), 199-222.

Thoman, D. B., Sansone, C., \& Geerling, D. (2017). The dynamic nature of interest: Embedding interest within self-regulation. In P. A. O’Keefe \& J. M. Harackiewicz (Eds.), The science of interest (pp. 27-47). Cham, Switzerland: Springer.

Wagner, R. K., \& Sternberg, R. J. (1985). Practical intelligence in real-world pursuits: The role of tacit knowledge. Journal of Personality and Social Psychology, 49(2), 436-458. 
Werner, K. M., \& Milyavskaya, M. (in press). We may not know what we want, but do we know what we need? Examining the ability to forecast need satisfaction in goal pursuit. Social Psychological and Personality Science.

Wolters, C. A. (2003). Regulation of motivation: evaluating an underemphasized aspect of selfregulated learning. Educational Psychologist, 38(4), 189-205.

Woolley, K., \& Fishbach, A. (2015). The experience matters more than you think: People value intrinsic incentives more inside than outside an activity. Journal of Personality and Social Psychology, 109(6), 968-982. 


\section{Recommended Readings}

MacGregor, K. E., Carnevale, J. J., Dusthimer, N. E., \& Fujita, K. (2017). See reference list.

- This paper presents several studies examining people's metamotivational knowledge about the benefits of focusing on the big picture (forest over trees) when encountering self-control conflicts.

Miele, D. B., \& Scholer, A. A. (2018). See reference list.

- This paper examines in more detail how individuals monitor their own motivational states and determine which strategies to employ. It also provides a review of a lot of prominent work in educational psychology.

Murayama, K., Kitagami, S., Tanaka, A., \& Raw, J. A. L. (2016). See reference list.

- This paper presents a study examining people's metamotivational beliefs about rewards - an example of how people sometimes get it wrong.

Scholer, A. A., \& Miele, D. B. (2016). See reference list.

- This paper presents several studies examining people's metamotivational knowledge about when eager versus vigilant motivation is optimal for performance, revealing ways in which people's beliefs are both accurate and inaccurate.

Wolters, C. A. (2003). See reference list.

- This is a classic paper bringing attention to the importance of examining motivation regulation. 